\title{
Salinity-induced heterokairy in an upper-estuarine population of the snail Radix balthica (Mollusca: Pulmonata)
}

\author{
Oliver Tills*, John I. Spicer, Simon D. Rundle \\ Marine Biology and Ecology Research Centre, University of Plymouth, Drake Circus, Plymouth PL4 8AA, UK
}

\begin{abstract}
Climate change is predicted to increase sea level and cause saline intrusion of coastal freshwaters. This will have consequences for freshwater organisms inhabiting such areas; developmental phenotypic plasticity may facilitate the persistence of freshwater species under such scenarios of increased salinity. Here we investigated developmental plasticity under different salinity treatments $(\mathrm{S}=2,5,7$ and 9 , with artificial pond water $[\mathrm{APW}]$ and deionised water $[\mathrm{S}=0]$ as controls) in embryos from an upper-estuarine population of the gastropod Radix balthica. We focused on plasticity in the timing of developmental events (heterokairy) at different salinities, including the time of onset (relative and absolute) of 10 developmental events and duration of 4 developmental stages; we also assessed whether salinity affected hatchling morphology and embryonic cardiac activity. There were significant differences in the absolute time of onset of several events with increased salinity, including a delayed first heartbeat in S5 and S7 compared with APW and in the relative time of onset of eye spot formation, first heartbeat and foot attachment between treatments. Stage duration also varied between salinity treatments: the hippo developmental stage lasted significantly longer in S7 compared with APW and development overall was prolonged in S7, with embryos in S9 not developing past the trochophore stage. Salinity also affected both shell size and shell shape of hatchlings. Hence salinity influences the time of onset (absolute and relative) of developmental events and duration of several developmental stages and the morphology of hatchling snails, although the mechanistic basis and fitness implications are, as yet, unknown.
\end{abstract}

KEY WORDS: Developmental phenotypic plasticity · Seawater intrusion · Embryonic development · Sequence changes

Resale or republication not permitted without written consent of the publisher

\section{INTRODUCTION}

Due to human-induced global warming, a significant global mean sea level rise is predicted during the 21st century, this rise being due primarily to both thermal expansion of the oceans and melting of glaciers and ice caps (IPCC 2001). The magnitude of global sea level rise is predicted to be 0.03 to $0.14 \mathrm{~m}$ by 2025 and 0.05 to $0.32 \mathrm{~m}$ by 2050 (IPCC 2001) and is expected to affect marine habitats in several ways, including upward shifts in species distributions, ecological changes resulting from altered habitat availability within particu- lar depth zones and drowning of some biogenic habitats whose accretion rates are outpaced by sea level rise (Knowlton 2001, Scavia et al. 2002, Harley et al. 2006). At the same time, global sea level rise is also expected to affect large areas of freshwater habitat via saline intrusion (Lee 2001).

Salinity influences the distribution of both freshwater and marine organisms (de Lafontaine 1990, Hart et al. 1991, Ahel et al. 1996, Yamamuro 2000). The abundance of freshwater species declines as salinity increases from 3 to 5 (Gainey \& Greenberg 1977), although some freshwater taxa can survive in brackish 
waters. It is possible that increased saline intrusion into freshwaters through sea level rise will compromise the physiology of such freshwater organisms from habitats that straddle the fresh-saline water transition. However, the physiological mechanisms freshwater species possess that allow them to survive saltwater intrusion are still not fully elucidated. Neither are the timescales on which different physiological and evolutionary mechanisms could operate.

The extent to which developmental phenotypic plasticity - the production of multiple phenotypes from a single genotype due to the influence of environmental conditions during development (Bradshaw 1965) - is a potential means by which some predominantly freshwater species might survive and persist in brackish water is relatively unexplored. Before the 1980s, much of the emphasis within developmental biology was on conservative aspects of development involving the suppression of deviant variation in order to produce a functional phenotype and, therefore, phenotypic plasticity was regarded more as environmental noise than a feature of development warranting study (discussed in West-Eberhard 1989). Over the past 2 decades, the importance of phenotypic plasticity has seen increased recognition and, as a result, has been the subject of intense study (West-Eberhard 1989, Agrawal 2001, Pigliucci 2001, Price et al. 2003, Spicer \& Rundle 2007). Such plasticity has been demonstrated in many taxa in response to a wide range of both biotic and abiotic stimuli (reviewed in Pigliucci 2001, DeWitt \& Scheiner 2004). Traditionally, investigations of phenotypic plasticity have examined morphological characters. Studies of physiological plasticity, on the other hand, have received scant attention until much more recently (Spicer \& Burggren 2003). Such physiological studies usually examine phenotypic plasticity with respect to differences in adult morphologies, with far fewer considering environmental effects during embryonic or juvenile development (Spicer \& Burggren 2003, Spicer \& Rundle 2007). One specific form of developmental phenotypic plasticity is heterokairy, defined as 'plasticity in the timing of the onset of developmental events at the level of an individual during its development' (Spicer \& Burggren 2003, p 92). Heterokairy is most easily identified through the study of developmental sequences. Changes in the relative timing of physiological events during development have been demonstrated to allow taxa to survive under stressful environmental conditions (Spicer \& El-Gamal 1999). Consequently, the study of this phenomenon is arguably critical to future studies of developmental plasticity.

Here we investigated the effect of different salinities on embryonic developmental plasticity in a brackish water population of the pulmonate snail Radix balthica. We wanted to know if salinity affected: (1) timing and/or sequence of the appearance of a number of key embryological features and events (e.g. veliger, first heartbeat, hatching); (2) post-hatch morphology; and (3) embryonic cardiac activity. R. balthica (formerly Lymnaea ovata and L. peregra) is common in freshwater systems throughout the UK, but also inhabits brackish waters in Northern Europe, e.g. UK estuaries and the Baltic Sea (Råberg \& Kautsky 2007, authors' pers. obs.), hence it is an ideal model system as it occurs in a range of salinities in situ. At the same time, its embryos develop within a transparent egg capsule allowing embryonic development to be monitored non-invasively (Smirthwaite et al. 2007).

\section{MATERIALS AND METHODS}

Stock population. Radix balthica adults were collected by hand during October 2007 from the intertidal zone of the upper Dart Estuary, Totnes, Devon, UK $\left(50^{\circ} 26^{\prime} 19^{\prime} \mathrm{N}, 3^{\circ} 41^{\prime} 24^{\prime} \mathrm{W}\right)$. This is a macrotidal, partially mixed estuary and our collection site was ca. $100 \mathrm{~m}$ upstream of an Environment Agency monitoring site at which the salinity (over a $10 \mathrm{yr}$ period) varied from 0.9 to 6.7 (Thain et al. 2004, Environment Agency pers. comm.). Snails were transported to the laboratory at Plymouth within $24 \mathrm{~h}$ of collection.

Experimental design. Snails were maintained in aquaria (13 l volume, max. stocking density 20 individuals per aquarium, $12 \mathrm{~h}$ light: $12 \mathrm{~h}$ dark cycle, $15^{\circ} \mathrm{C}$ ) filled with aerated artificial pond water (APW) (ASTM 1980) with $90 \mathrm{mg} \mathrm{l}^{-1}\left[\mathrm{Ca}^{2+}\right.$ (Rundle et al. 2004). Water in the aquaria was changed every $7 \mathrm{~d}$. Snails were fed ad libitum on lettuce and spinach.

Radix balthica is a mixed mating, simultaneous hermaphrodite typically laying from 50 to 100 eggs within an egg mass (Jarne \& Delay 1990, Wiehn et al. 2002, Jokela et al. 2006, authors' pers. obs.). Egg masses deposited by snails from the stock population were removed and examined under high power magnification (75×, Leica MZ12). Eggs that had not developed past the 2-cell division stage, which occurs within 2 to $3 \mathrm{~h}$ of oviposition (Morrill 1982), were gently extricated from egg masses under low power microscopy $(10 \times)$ and placed individually in treatment water (24 replicates per treatment) within single-cell culture wells ( $2 \mathrm{ml}$ volume per well, 24 wells per tray). Eggs were evenly distributed from each egg mass between the treatment solutions to prevent any bias possibly resulting from differences in development between eggs from different egg masses. Eggs were also randomly allocated to each treatment solution from within each egg mass to prevent any bias that could be caused by differences as a result of location in the egg mass. Due to differences in the size of egg masses produced, the 
number of eggs in each egg mass was not constant. Consequently, the number of eggs used in a treatment from a single egg mass ranged from 4 to 8, although the number of eggs from a particular egg mass was constant across treatments. Four egg masses were used overall. Individual culture trays contained only eggs cultured within the same treatment solution in order to prevent contamination of one treatment solution by another between wells. Culture trays were housed within a controlled-temperature facility $\left(20^{\circ} \mathrm{C}\right)$ under a $12 \mathrm{~h}$ light:12 h dark cycle. Treatment solution in each of the wells was changed daily under low power microscopy.

Stock solutions. Eggs were cultured under salinities of 2, 5, 7 and 9 (S2, S5, S7 and S9) (Carlsson 2006) and under control regimes of APW and deionised water (salinity of 0, S0). Brackish water treatments were constructed by dissolving the appropriate amount of Instant Ocean ${ }^{\circledR}$ in deionised water and salinity was measured using a digital salinity meter (YSI 30-10 conductivity meter). Both S0 and APW were used as control solutions as APW is likely to most closely represent water conditions in situ and S0 was the base upon which salinity treatments were constructed. Stock solutions were maintained in sealed glass bottles in a controlled-temperature facility $\left(20^{\circ} \mathrm{C}\right)$ for at least $24 \mathrm{~h}$ before use. The salinity of brackish water treatments was measured every $7 \mathrm{~d}$ with a digital salinity meter to ensure it remained constant throughout the study period. Solutions all remained within 0.1 of their original salinity during the course of the study and all stock solutions constructed at the beginning of the study lasted to the end of the study period.
Developmental sequences and cardiac activity. Eggs were examined daily under high power microscopy and the event in the developmental itinerary they had reached was recorded; developmental events, and the criteria used for their identification, were taken from Smirthwaite et al. (2007) (Table 1). Embryos grew, over a period of approximately $10 \mathrm{~d}$, from 0.2 to $0.9 \mathrm{~mm}$ length, at which size they hatched. Embryos were monitored for several minutes to identify the first occurrence of non-morphological developmental events, such as the appearance of the first heartbeat. The developmental stages trochophore, veliger and hippo were analysed both as an event (time of onset) and duration (length).

Cardiac activity (beats $\mathrm{min}^{-1}$ ) in each individual was monitored daily under high power magnification once the heart had begun beating, by counting the number of heartbeats in a $15 \mathrm{~s}$ time period.

Shell morphology. Once hatched, individuals were preserved in microcentrifuge tubes (Eppendorf, $0.6 \mathrm{ml}$ volume) containing $70 \%$ ethanol. Digital images of each shell were obtained (Nikon Coolpix 4500 digital camera) by placing the preserved shells on agar plates with a $10 \mathrm{~mm}$ scale bar (0.1 $\mathrm{mm}$ graduations); it was necessary to use agar plates as shells were very fragile and therefore easily broken if placed on harder surfaces. Aspects of the shell morphology (length, width, aperture height, aperture length and aperture width; Fig. 1) were quantified through analysis of the digital images obtained (UTHSCSA Image Tool for Windows, version 3). Ratios of length to width (aspect ratio), aperture length to aperture width (aperture ratio) and length to aperture height were calculated to provide measures of change in shell shape.

Table 1. Radix balthica. Descriptions of the developmental events and stages. Each event was recorded when it was first observed and the duration of developmental stages was also recorded, observations were made every $24 \mathrm{~h}$. After Smirthwaite et al. (2007)

\begin{tabular}{|c|c|}
\hline Developmental stage & Description of stage \\
\hline Blastula/gastrula & Cell division stage, polar bodies present \\
\hline Spinning activity & Rotating using cilia \\
\hline Trochophore stage & Spherical liver cells form a helmet like velum within the egg \\
\hline Veliger stage & Foot formation and shell secretion. Symmetrical development of 2 ends of the embryo \\
\hline Hippo stage & $\begin{array}{l}\text { Asymmetrical development with further development of the foot and shell; this is the major stage } \\
\text { of organogenesis, the head becomes more conspicuous from the rest of the body, as the middle } \\
\text { part is pinched in }\end{array}$ \\
\hline Ontogeny of eyes & Formed on the head, further pigmentation of eye spots occurs as they develop \\
\hline First heartbeat & $\begin{array}{l}\text { First beat of the chamber-type heart which forms on the far back of the shell and moves closer } \\
\text { towards the head as the embryo grows }\end{array}$ \\
\hline Initial foot attachment & Foot attaches to the capsule wall enabling the embryo to crawl \\
\hline Radula activity & The radula situated in the head starts actively sucking in the capsular fluid \\
\hline Hatching & Rupture of the egg capsule, enabling the embryo to emerge \\
\hline
\end{tabular}




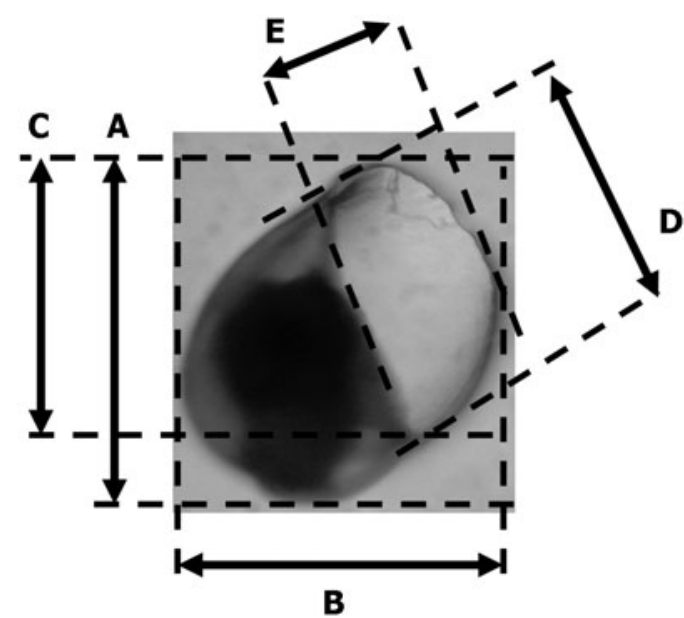

Fig. 1. Radix balthica. Shell dimensions measured in the analysis of shell morphology. Arrows indicate the distance measured. A: length; B: width; C: aperture height; D: aperture length; E: aperture width

Analytical approach. A 2-way general linear model, run in SPSS, was used to test for differences between salinity treatments (fixed factor) and egg mass (random factor) in: (1) time of onset of developmental events; (2) duration of developmental stages; and (3) shell morphology of hatchlings. Estimated marginal means were used to facilitate pair-wise post hoc comparisons, using Sidak tests, between levels within a main effect where an interaction potentially confounds this (SPSS).

In order to test for differences in the relative timing of events between treatments, a timeline was produced for each embryo whereby each event was given a score based on its position in the order of occurrence. Event sequences were then compared with the standard sequence for Radix balthica determined by Smirthwaite et al. (2007) and binary coding was used to score events depending on if they occurred in a different (1) or the same (0) position in the sequence; events were also given a score of 0 if their precise timing was unknown (i.e. if their onset did not occur during the observation period). These binary data were analysed using a generalised linear mixed model with salinity treatment as a fixed factor and egg batch as a random factor; the Wald test statistic, with a bimodal error distribution, was used to test for differences between treatments.

\section{RESULTS}

\section{Time of onset of developmental events}

There was delayed onset of several developmental events with increased salinity, determined mostly by the late onset of events in the S5 and S7 treatments relative to the control APW and S0 treatments, including spinning, trochophore, veliger, eyes, heart, foot and hatching (Tables $2 \& 3$ ).

The time of onset of the developmental events spinning $(\mathrm{p} \leq 0.001)$ and trochophore $(\mathrm{p}=0.012)$ were significantly later in the S0 treatment relative to APW and several early developmental events occurred later in the S0 treatment compared with higher salinity treatments (spinning: S0 vs. S2, p $\leq 0.001$; S0 vs. S5, $\mathrm{p}=0.015$; S0 vs. S7, $\mathrm{p} \leq 0.001$; trochophore: S0 vs. S2, $p=0.01 ;$ S0 vs. S5, p = 0.041). The time of onset of the events eyes, heartbeat and hatching differed between egg masses, driven almost entirely by the late onset of events in embryos from egg mass D relative to other egg masses (Table 4). Salinity-induced plasticity in the time of onset of spinning, trochophore, veliger, hippo and foot attachment differed between egg masses, as indicated by a salinity $\times$ egg mass interaction.

\section{Sequence of developmental events}

There were differences in the relative timing of several developmental events between treatments (Fig. 2). The appearance of eye spots, heartbeat and foot attachment occurred in significantly different positions within the sequence of developmental events between treatments (Wald test: eye spots, $\chi^{2}{ }_{4}=$ 36.4, $\mathrm{p} \leq 0.001$; heart, $\chi_{4}^{2}=15.32, \mathrm{p}=0.004$; foot attachment, $\chi_{4}^{2}=9.96, \mathrm{p}=0.041$ ). Foot attachment occurred earlier within the sequence of developmental events in some embryos from all treatments compared with Smirthwaite et al. (2007) (percentage occurrence: APW, 25\%; S0, 46\%; S2, 36\%; S5, $63 \%$; $\mathrm{S} 7,60 \%)$, and first heartbeat later in the S2 (5\%), S5 $(50 \%)$ and $\mathrm{S} 7(50 \%)$ treatments, as well as in the S0 treatment $(21 \%)$. Eye spots appeared later within the sequence of developmental events in $5 \%$ of embryos cultured in the S2 treatment and $13 \%$ of embryos from the S5 treatment.

\section{Duration of developmental stages}

The duration of the cell division developmental stage was prolonged in embryos cultured under increased salinity (Tables $5 \& 6$ ). There was a significant treatment $\times$ egg mass interaction on the duration of the cell division, trochophore and veliger stages and there was a significant effect of egg mass on the duration of all developmental stages, driven largely by differences between egg mass D relative to other egg masses (Table 7). 
Table 2. Results of 2-way ANOVAs assessing differences in the time of onset of developmental events in Radix balthica between treatments and egg masses. ${ }^{*}: p<0.05_{i * *}^{* *}: p \leq 0.001 ;{ }^{\text {ns }}: p>0.05$

\begin{tabular}{|c|c|c|c|c|c|}
\hline Factor & $\mathrm{df}$ & SS & MS & $F$ & $\mathrm{p}$ \\
\hline \multicolumn{6}{|l|}{ Spinning } \\
\hline Treatment & 5 & 26.632 & 5.326 & 11.564 & $0.001^{* * *}$ \\
\hline Error & 14.661 & 6.753 & 0.461 & & \\
\hline Egg mass & 3 & 3.62 & 1.207 & 2.613 & $0.091^{\mathrm{ns}}$ \\
\hline Error & 14.630 & 6.756 & 0.462 & & \\
\hline Treatment $\times$ Egg mass & 14 & 6.838 & 0.488 & 3.649 & $\leq 0.001^{* * *}$ \\
\hline Error & 95 & 12.717 & 0.134 & & \\
\hline \multicolumn{6}{|l|}{ Trochophore } \\
\hline Treatment & 5 & 27.215 & 5.443 & 14.807 & $\leq 0.001^{* * *}$ \\
\hline Error & 15.435 & 5.674 & 0.368 & & \\
\hline Egg mass & 3 & 23.405 & 7.802 & 21.109 & $\leq 0.001^{* * *}$ \\
\hline Error & 15.263 & 5.641 & 0.37 & & \\
\hline Treatment $\times$ Egg mass & 14 & 5.407 & 0.386 & 2.059 & $0.021^{*}$ \\
\hline Error & 92 & 17.258 & 0.188 & & \\
\hline \multicolumn{6}{|l|}{ Veliger } \\
\hline Treatment & 5 & 9.675 & 1.935 & 5.351 & $0.007^{*}$ \\
\hline Error & 12.571 & 4.546 & 0.362 & & \\
\hline Egg mass & 3 & 5.236 & 1.745 & 4.733 & $0.02^{*}$ \\
\hline Error & 12.483 & 4.604 & 0.369 & & \\
\hline Treatment $\times$ Egg mass & 12 & 4.989 & 0.416 & 7.508 & $\leq 0.001^{* * *}$ \\
\hline Error & 79 & 4.375 & 0.055 & & \\
\hline \multicolumn{6}{|l|}{ Hippo } \\
\hline Treatment & 4 & 6.452 & 1.613 & 2.078 & $0.146^{\mathrm{ns}}$ \\
\hline Error & 12.115 & 9.405 & 0.776 & & \\
\hline Egg mass & 3 & 11.199 & 3.733 & 5.175 & $0.015^{*}$ \\
\hline Error & 12.283 & 8.861 & 0.721 & & \\
\hline Treatment $\times$ Egg mass & 12 & 9.839 & 0.82 & 12.791 & $\leq 0.001^{* * *}$ \\
\hline Error & 78 & 5 & 0.064 & & \\
\hline \multicolumn{6}{|l|}{ Eyes } \\
\hline Treatment & 4 & 10.013 & 2.503 & 7.461 & $0.002^{*}$ \\
\hline Error & 13.223 & 4.436 & 0.335 & & \\
\hline Egg mass & 3 & 48.159 & 16.053 & 47.850 & $\leq 0.001^{* * *}$ \\
\hline Error & 12.555 & 4.212 & 0.335 & & \\
\hline Treatment $\times$ Egg mass & 11 & 3.69 & 0.335 & 1 & $0.454^{\mathrm{ns}}$ \\
\hline Error & 76 & 25.492 & 0.335 & & \\
\hline \multicolumn{6}{|l|}{ Heart } \\
\hline Treatment & 4 & 22.042 & 5.51 & 14.572 & $\leq 0.001^{* * *}$ \\
\hline Error & 12.948 & 4.896 & 0.378 & & \\
\hline Egg mass & 3 & 31.994 & 10.665 & 28.118 & $\leq 0.001^{* * *}$ \\
\hline Error & 12.364 & 4.689 & 0.379 & & \\
\hline Treatment $\times$ Egg mass & 11 & 4.204 & 0.382 & 1.136 & $0.346^{\mathrm{ns}}$ \\
\hline Error & 76 & 25.567 & 0.336 & & \\
\hline \multicolumn{6}{|l|}{ Foot } \\
\hline Treatment & 4 & 15.739 & 3.935 & 3.584 & $0.038^{*}$ \\
\hline Error & 12.046 & 13.224 & 1.098 & & \\
\hline Egg mass & 3 & 33.793 & 11.264 & 10.127 & $\leq 0.001^{* * *}$ \\
\hline Error & 11.735 & 13.053 & 1.112 & & \\
\hline Treatment $\times$ Egg mass & 11 & 12.659 & 1.151 & 2.084 & $0.032^{*}$ \\
\hline Error & 76 & 41.967 & 0.552 & & \\
\hline \multicolumn{6}{|l|}{ Radula } \\
\hline Treatment & 4 & 3.93 & 0.983 & 1.585 & $0.239^{\mathrm{ns}}$ \\
\hline Error & 12.514 & 7.755 & 0.62 & & \\
\hline Egg mass & 3 & 44.204 & 14.735 & 23.593 & $\leq 0.001^{* * *}$ \\
\hline Error & 12.062 & 7.533 & 0.625 & & \\
\hline Treatment $\times$ Egg mass & 11 & 7.01 & 0.637 & 1.451 & $0.168^{\mathrm{ns}}$ \\
\hline Error & 76 & 33.375 & 0.439 & & \\
\hline \multicolumn{6}{|l|}{ Hatching } \\
\hline Treatment & 4 & 60.903 & 15.266 & 11.945 & $\leq 0.001^{* * *}$ \\
\hline Error & 14.333 & 18.269 & 1.275 & & \\
\hline Egg mass & 3 & 139.484 & 46.495 & 36.913 & $\leq 0.001^{* * *}$ \\
\hline Error & 13.305 & 16.759 & 1.26 & & \\
\hline Treatment $\times$ Egg mass & 11 & 13.427 & 1.221 & 0.662 & $0.769^{\mathrm{ns}}$ \\
\hline Error & 71 & 130.879 & 1.843 & & \\
\hline
\end{tabular}

\section{Survival through to hatching}

The greatest level of survival (100\%) was recorded for embryos developing in the So treatment, whereas survival of embryos in salinity treatments decreased with increased salinity, from $91 \%$ survival in $\mathrm{S} 2$ to $0 \%$ in S9 (Fig. 3). No embryos developed past the veliger stage in the S9 treatment (Fig. 2); their cellular material became scattered across the egg capsule at this stage and no further development occurred. There was a high degree of variation in survival between egg masses across treatments that increased to a range of 0 to $100 \%$ in the S7 treatment (Fig. 4).

\section{Hatchling shell morphology}

There was a significant effect of salinity on length, aspect ratio and aperture ratio (Table 8). Despite there being no obvious trend in shell morphology with an increase in salinity from 2 to 7 , the aperture ratio was less in S2 ( $p=0.001)$, S5 $(p=0.002)$ and S7 ( $p=0.001)$ treatments compared with S0, and shell length was significantly smaller in the S7 treatment compared with shells from the APW treatment ( $p=0.012$; Fig. 5).

Shell width and the body length:aperture height ratio differed between egg masses and there was a treatment $\times$ egg mass interaction in the aperture height of hatchling shells (Table 6).

Hatchlings from the S0 treatment, relative to APW, had a significantly smaller aperture width $(\mathrm{p}=0.007)$, aperture height ( $p \leq 0.001)$, shell length $(p \leq 0.001)$ and aspect ratio (i.e. they were more rotund, $\mathrm{p}=0.016)$ and a greater aperture ratio $(\mathrm{p}=$ 0.035). That there were differences in shell morphology between embryos cultured in a salinity of 0 and those from other treatments is perhaps not surprising given the absence of external ions available for shell production in the S0 treatment.

\section{Cardiac activity}

The highest (132 beats $\mathrm{min}^{-1}$ ) and lowest (28 beats $\mathrm{min}^{-1}$ ) mean heart rates were recorded from embryos cultured in $\mathrm{S} 7$. 
Table 3. Results of pair-wise treatment comparisons of the time of onset of developmental events. See Fig. 2 for description of treatments

\begin{tabular}{|c|c|c|}
\hline & Treatments & $\mathrm{p}$ \\
\hline Spinning & $\begin{array}{l}\text { APW vs S7 } \\
\text { APW vs S9 } \\
\text { S0 vs S9 } \\
\text { S2 vs S7 } \\
\text { S2 vs S9 } \\
\text { S5 vs S9 } \\
\text { S7 vs S9 }\end{array}$ & $\begin{aligned} & 0.015 \\
\leq & 0.001 \\
\leq & 0.001 \\
& 0.005 \\
\leq & 0.001 \\
\leq & 0.001 \\
\leq & 0.001\end{aligned}$ \\
\hline Trochophore & $\begin{array}{l}\text { APW vs S7 } \\
\text { APW vs S9 } \\
\text { S0 vs S9 } \\
\text { S2 vs S7 } \\
\text { S2 vs S9 } \\
\text { S5 vs S9 } \\
\text { S7 vs S9 }\end{array}$ & $\begin{aligned} & 0.036 \\
\leq & 0.001 \\
\leq & 0.001 \\
& 0.03 \\
\leq & 0.001 \\
\leq & 0.001 \\
\leq & 0.001\end{aligned}$ \\
\hline Veliger & $\begin{array}{l}\text { APW vs S7 } \\
\text { APW vs S9 } \\
\text { S2 vs S7 } \\
\text { S2 vs S9 } \\
\text { S5 vs S7 } \\
\text { S5 vs S9 }\end{array}$ & $\begin{array}{l}\leq 0.001 \\
\leq 0.001 \\
\leq 0.001 \\
\leq 0.001 \\
\leq 0.001 \\
\leq 0.001\end{array}$ \\
\hline Eyes & $\begin{array}{l}\text { APW vs S7 } \\
\text { S0 vs S7 } \\
\text { S2 vs S7 }\end{array}$ & $\begin{array}{l}\leq 0.009 \\
\leq 0.014 \\
\leq 0.006\end{array}$ \\
\hline Heart & $\begin{array}{l}\text { APW vs S5 } \\
\text { APW vs S7 } \\
\text { S0 vs } S 7 \\
\text { S2 vs } S 5 \\
\text { S2 vs } S 7 \\
\text { S5 vs } S 7\end{array}$ & $\begin{array}{r}0.002 \\
\leq 0.001 \\
\leq 0.001 \\
0.018 \\
\leq 0.001 \\
0.016\end{array}$ \\
\hline Foot & $\begin{array}{l}\text { S0 vs S7 } \\
\text { S2 vs S5 } \\
\text { S2 vs S7 }\end{array}$ & $\begin{array}{l}0.025 \\
0.002 \\
0.002\end{array}$ \\
\hline Hatch & $\begin{array}{l}\text { APW vs S7 } \\
\text { S0 vs S7 } \\
\text { S2 vs S7 } \\
\text { S5 vs S7 }\end{array}$ & $\begin{array}{r}\leq 0.001 \\
0.045 \\
\leq 0.001 \\
0.011\end{array}$ \\
\hline
\end{tabular}

Heart rate increased as development progressed (Fig. $6)$; this trend became less clearly defined later in development, which appears largely due to the few abnormal embryos in treatments which took longer to hatch than the majority of embryos cultured.

\section{DISCUSSION}

Here we demonstrated the occurrence of heterokairy, in terms of the time of onset of developmental events (both relative and absolute) and duration of developmental stages, in response to salinity in an upper-estuarine population of Radix balthica. Salinityrelated sequence heterokairy occurred during midembryonic development. For snails cultured in APW, the heartbeat and eye appeared simultaneously and
Table 4. Radix balthica. Pair-wise egg mass comparisons of time of onset of developmental events in control treatments of artificial pond water (APW) and deionised water (salinity of 0 , S0) and treatments of salinities of 2, 5 and 7 (S2, S5 and S7). A, $\mathrm{B}, \mathrm{C}$ and D: individual egg masses. Only treatments containing significant egg mass pair-wise differences are included. Blank cells indicate no significant difference

\begin{tabular}{|c|c|c|c|c|}
\hline $\begin{array}{l}\text { Event } \\
\text { Treatment }\end{array}$ & A vs. B & A vs. D & B vs. D & C vs. D \\
\hline \multicolumn{5}{|l|}{ Eyes } \\
\hline APW & & $\leq 0.001$ & $\leq 0.001$ & $\leq 0.001$ \\
\hline So & & $\leq 0.001$ & $\leq 0.001$ & $\leq 0.001$ \\
\hline $\mathrm{S} 2$ & & $\leq 0.001$ & $\leq 0.001$ & 0.014 \\
\hline S5 & & 0.003 & $\leq 0.001$ & $\leq 0.001$ \\
\hline \multicolumn{5}{|l|}{ Heart } \\
\hline APW & & $\leq 0.001$ & $\leq 0.001$ & $\leq 0.001$ \\
\hline S0 & & $\leq 0.001$ & 0.004 & $\leq 0.001$ \\
\hline $\mathrm{S} 2$ & & 0.003 & $\leq 0.001$ & 0.003 \\
\hline $\mathrm{S} 7$ & 0.049 & & & \\
\hline \multicolumn{5}{|l|}{ Hatching } \\
\hline APW & & 0.001 & 0.001 & 0.001 \\
\hline So & & 0.001 & 0.003 & 0.001 \\
\hline $\mathrm{S} 2$ & & 0.034 & & \\
\hline S5 & & & 0.015 & 0.015 \\
\hline
\end{tabular}

before the attachment of the foot, whereas at a salinity of 2, foot attachment occurred in some individuals before the appearance of the eyes which, in turn, appeared before the heart began beating. Furthermore, culture in even higher salinities (S5 and S7) also led to sequence heterokairy with the eyes appearing before foot attachment, which, in turn, commenced before the appearance of the heartbeat. Hence, altered timing occurred in a range of developmental events, with only the initiation of the hippo stage and onset of radula activity occurring at the same time with increased salinity.

While developmental phenotypic plasticity has attracted considerable interest in recent years (Pigliucci 1998, 2005, West-Eberhard 2003, 2005, Brakefield 2006), less attention has been given to heterokairy, which refers specifically to changes in the sequence and timing of events during development (Spicer \& Burggren 2003, Spicer \& Rundle 2007). However, the evidence for such changes is accumulating, from investigations which explicitly set out to test for heterokairy (e.g. Black \& Burggren 2004, Blacker et al. 2004, Bagatto 2005, Warkentin 2007) and those where the pattern was found but not described explicitly as such (see Spicer \& Rundle 2007 for examples).

The present study provides further evidence for the occurrence of heterokairy as a pattern. What is still not clear, however, is the extent to which this phenomenon of heterokairy as a pattern is underpinned by heterokairic mechanisms, i.e. changes in the sequence of gene expression. If heterokairy is a process as well as a 
Fig. 2. Radix balthica. Mean timing of developmental events and stages between artificial pond water (APW), deionised water $(S=0)$, and different salinity treatments $(S=2,5,7$ and 9). Developmental events are marked by letter: A: blastula/gastrula; B: spinning; C: trochophore; $\mathrm{D}$ : veliger; $\mathrm{E}$ : hippo; F: eyes; G, heart; H: foot attachment; I: radula; J: hatching. Developmental stages are indicated by different shades

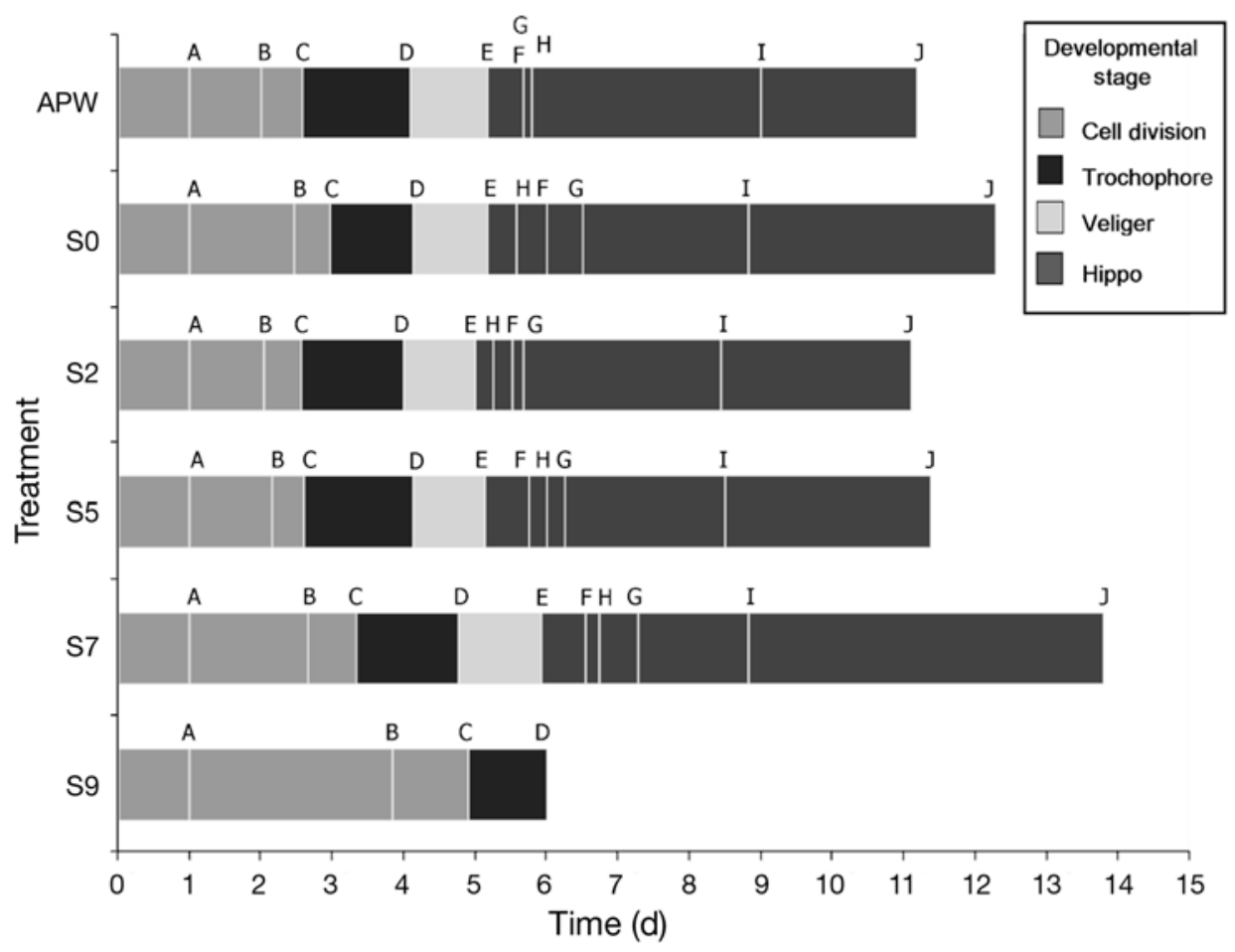

Table 5. Results of two-way ANOVAs assessing differences in the duration of developmental stages in Radix balthica between treatments and egg masses. ${ }^{*}: \mathrm{p}<0.05{ }^{* * *}: \mathrm{p} \leq 0.001{ }^{\text {ns }}: \mathrm{p}>0.05$

\begin{tabular}{|lcrccc|}
\hline Factor & $\mathrm{df}$ & $\mathrm{SS}$ & $\mathrm{MS}$ & $F$ & $\mathrm{p}$ \\
\hline Cell division & & & & & \\
Treatment & 5 & 27.215 & 5.443 & 14.807 & $\leq 0.001^{* * *}$ \\
Error & 15.435 & 5.674 & 0.368 & & \\
Egg mass & 3 & 23.405 & 7.802 & 21.109 & $\leq 0.001^{* * *}$ \\
Error & 15.263 & 5.641 & 0.37 & & \\
Treatment $\times$ Egg mass & 14 & 5.407 & 0.386 & 2.059 & $0.021^{*}$ \\
Error & 92 & 17.258 & 0.188 & & \\
Trochophore & & & & & \\
Treatment & 5 & 2.798 & 0.56 & 1.497 & $0.252^{\text {ns }}$ \\
Error & 14.301 & 5.345 & 0.34 & & \\
Egg Mass & 3 & 35.513 & 11.838 & 31.35 & $\leq 0.001^{* * *}$ \\
Error & 13.94 & 5.264 & 0.378 & & \\
Treatment $\times$ Egg mass & 12 & 4.832 & 0.403 & 1.914 & $0.045^{*}$ \\
Error & 79 & 16.617 & 0.21 & & \\
Veliger & & & & & \\
Treatment & 4 & 0.055 & 0.109 & 0.961 & $0.463^{\text {ns }}$ \\
Error & 12.382 & 0.288 & 0.113 & & \\
Egg mass & 3 & 0.152 & 0.405 & 3.789 & $0.038^{\text {ns }}$ \\
Error & 12.941 & 0.257 & 0.107 & & \\
Treatment $\times$ Egg mass & 12 & 0.198 & 0.118 & 3.884 & $\leq 0.001^{* * *}$ \\
Error & 78 & 2.375 & 0.03 & & \\
Hippo & & & & & \\
Treatment & 4 & 49.586 & 12.397 & 15.966 & $\leq 0.001^{* * *}$ \\
Error & 16.407 & 12.739 & 0.776 & & \\
Egg mass & 3 & 103.982 & 34.661 & 46.015 & $\leq 0.001^{* * *}$ \\
Error & 14.715 & 11.084 & 0.753 & & \multirow{2}{*}{$0.943^{\text {ns }}$} \\
Treatment $\times$ Egg mass & 11 & 7.627 & 0.693 & 0.42 & \\
Error & 71 & 117.307 & 1.652 & & \\
\hline
\end{tabular}

pattern, it may act as a mechanism for selection by increasing fitness and thus play an important role in evolution (see Spicer \& Rundle 2007 for discussion).

Although heterokairy may have adaptive significance (e.g. Warkentin 1995), it could also have negative effects on fitness (Spicer \& Burggren 2003). Gotthard \& Nylin (1995) comment that not all phenotypic plasticity has to be adaptive and that an organism exposed to environmental conditions with which it is unfamiliar, in terms of its evolutionary history, is highly likely to show non-adaptive phenotypic plasticity (discussed in Garland \& Kelly 2006). Heterokairy exhibited in response to salinity in the present study could indeed represent an adaptive shift in early embryonic development to enable individuals to in some way cope with the osmotic stress of development in brackish waters. However, the mechanisms involved are not clear and we are left with conjecture. On the other hand, the effect of salinity could be negative, delaying the construction of one physiological function during development relative to another. Only at a salinity of 7 was development significantly prolonged compared with that in freshwater (mainly due to a prolonged 
Table 6. Results of pair-wise treatment comparisons of the duration of developmental stages. See Fig. 2 for description of treatments

\begin{tabular}{|llc|}
\hline & Treatments & $\mathrm{p}$ \\
\hline Trochophore & APW vs S7 & 0.036 \\
& APW vs S9 & $\leq 0.001$ \\
& S0 vs S9 & $\leq 0.001$ \\
& S2 vs S7 & 0.03 \\
& S2 vs S9 & $\leq 0.001$ \\
& S5 vs S9 & $\leq 0.001$ \\
Veliger & APW vs S7 & 0.001 \\
& S2 vs S7 & 0.003 \\
& S5 vs S7 & 0.018 \\
\hline
\end{tabular}

Table 7. Radix balthica. Pair-wise egg mass comparisons of duration of developmental stages in control treatments of artificial pond water (APW) and deionised water (salinity of $0, \mathrm{~S} 0$ ) and treatments of salinities of 2, 5 and 7 (S2, S5 and S7). A, B, $\mathrm{C}$ and D: individual egg masses. Only treatments containing significant egg mass pair-wise differences are included. Blank cells indicate no significant difference

\begin{tabular}{|c|c|c|c|c|}
\hline $\begin{array}{l}\text { Event } \\
\text { Treatment }\end{array}$ & A vs. B & A vs. D & B vs. D & C vs. D \\
\hline \multicolumn{5}{|c|}{ Cell division } \\
\hline APW & & $\leq 0.001$ & 0.002 & 0.032 \\
\hline So & 0.003 & 0.002 & $\leq 0.001$ & $\leq 0.001$ \\
\hline $\mathrm{S} 2$ & & 0.001 & 0.002 & \\
\hline S5 & & 0.002 & 0.002 & 0.013 \\
\hline S7 & & $\leq 0.001$ & & \\
\hline \multicolumn{5}{|c|}{ Trocophore } \\
\hline APW & & $\leq 0.001$ & $\leq 0.001$ & 0.002 \\
\hline S0 & 0.007 & $\leq 0.001$ & $\leq 0.001$ & $\leq 0.001$ \\
\hline $\mathrm{S} 2$ & & 0.002 & 0.005 & \\
\hline S5 & & $\leq 0.001$ & $\leq 0.001$ & $\leq 0.001$ \\
\hline S7 & & $\leq 0.001$ & $\leq 0.001$ & 0.004 \\
\hline \multicolumn{5}{|l|}{ Veliger } \\
\hline S7 & & $\leq 0.001$ & $\leq 0.001$ & $\leq 0.001$ \\
\hline \multicolumn{5}{|l|}{ Hippo } \\
\hline APW & & $\leq 0.001$ & $\leq 0.001$ & 0.003 \\
\hline So & & 0.003 & 0.013 & 0.003 \\
\hline $\mathrm{S} 2$ & & 0.044 & 0.021 & \\
\hline S5 & & & 0.044 & 0.044 \\
\hline
\end{tabular}

hippo developmental stage), and it is difficult to see this as other than a pathological, and not an adaptive, feature.

Hatchlings from the S7 treatment had reduced shell length compared with those from the APW treatment. Altered shell morphology, in response to salinity very early in shell development, may translate to even greater differences in shell morphology in adults from embryos cultured within salinity regimes compared with those from freshwater. Shell aspect and aperture ratios were also altered between treatments. Radix balthica has been shown to modify its shell shape in

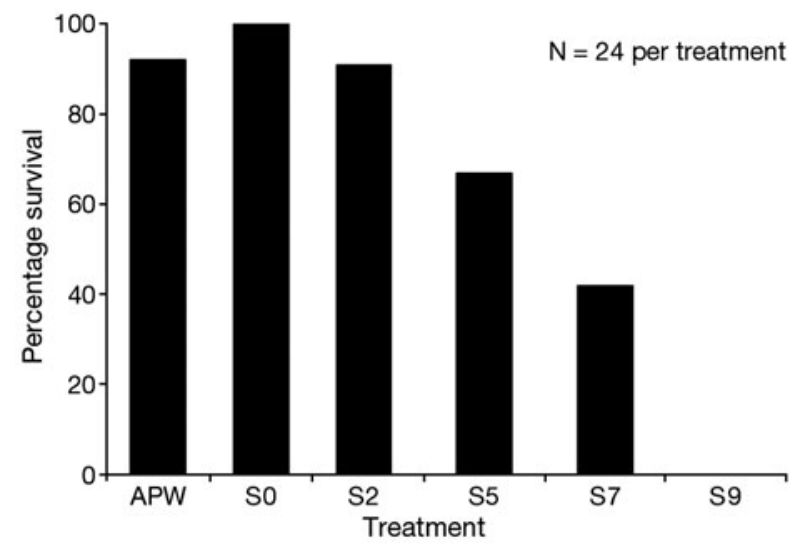

Fig. 3. Radix balthica. Percentage survival to hatching of embryos cultured within different treatments. See Fig. 1 for description of treaments

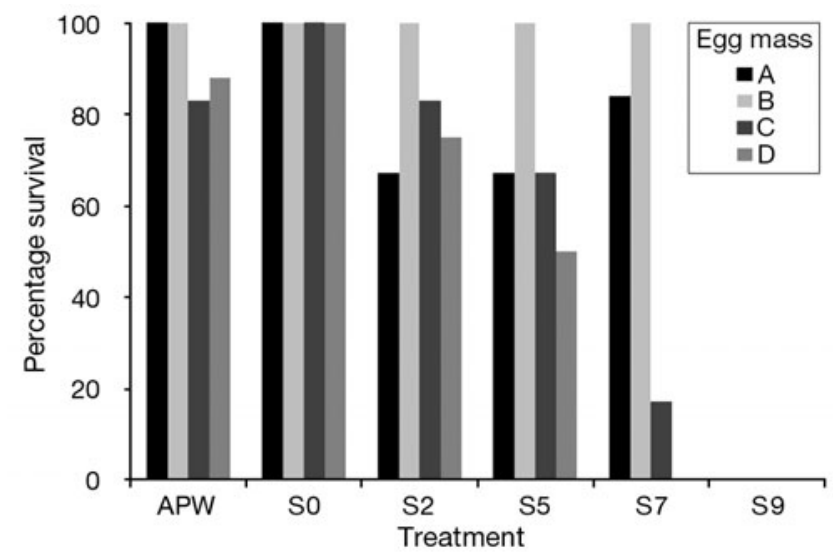

Fig. 4. Radix balthica. Percentage survival to hatching of embryos from individual egg masses (A, B, C and D) in different treatment solutionss. See Fig. 1 for description of treaments

response to the nature of predation threat (Lakowitz et al. 2008) and habitat type (Lam \& Calow 1988, Pfenninger et al. 2006); however, how differences in the shell development of the newly hatched snail arise, and their effect on the adult phenotype merits further attention. Embryos were exposed to constant salinity throughout development, which is unlikely to represent current in situ conditions for this upper-estuarine population or be entirely representative of future conditions at the collection site under forecasted future sea level rise. What is uncertain from our results is whether a brief, or periodic (as is likely to be the case for this upper-estuarine population), exposure to brackish waters early in development would elicit a change in shell morphology of hatchlings or, similarly, whether returning hatchlings cultured within brackish water to freshwater would see a return in shell morphology to that observed in hatchlings from freshwater. Relyea 
Table 8. Results of 2-way ANOVAs assessing the effect of culture in different treatment solutions on shell morphology of Radix balthica. ${ }^{*}: \mathrm{p}<0.05$; ${ }^{* * *}: \mathrm{p} \leq 0.001{ }^{\mathrm{ns}}: \mathrm{p}>0.05$

\begin{tabular}{|c|c|c|c|c|c|}
\hline Factor & $\mathrm{df}$ & SS & MS & $F$ & $\mathrm{p}$ \\
\hline \multicolumn{6}{|l|}{ Length } \\
\hline Treatment & 4 & 0.192 & 0.048 & 6.558 & $0.006^{*}$ \\
\hline Error & 11.317 & 0.083 & 0.007 & & \\
\hline Egg mass & 3 & 0.059 & 0.02 & 2.7 & $0.094^{\mathrm{ns}}$ \\
\hline Error & 11.709 & 0.085 & 0.007 & & \\
\hline Treatment $\times$ Egg mass & 10 & 0.075 & 0.008 & 1.445 & $0.189^{\mathrm{ns}}$ \\
\hline Error & 49 & 0.256 & 0.005 & & \\
\hline \multicolumn{6}{|l|}{ Width } \\
\hline Treatment & 4 & 0.042 & 0.01 & 2.755 & $0.076^{\mathrm{ns}}$ \\
\hline Error & 12.471 & 0.047 & 0.004 & & \\
\hline Egg mass & 3 & 0.053 & 0.018 & 4.66 & $0.02^{*}$ \\
\hline Error & 13.223 & 0.05 & 0.004 & & \\
\hline Treatment $\times$ Egg mass & 10 & 0.037 & 0.004 & 0.784 & $0.644^{\mathrm{ns}}$ \\
\hline Error & 49 & 0.231 & 0.005 & & \\
\hline \multicolumn{6}{|l|}{ Aperture height } \\
\hline Treatment & 4 & 0.053 & 0.013 & 2.505 & $0.103^{\text {ns }}$ \\
\hline Error & 10.919 & 0.057 & 0.005 & & \\
\hline Egg mass & 3 & 0.044 & 0.015 & 2.804 & $0.088^{\mathrm{ns}}$ \\
\hline Error & 11.191 & 0.058 & 0.005 & & \\
\hline Treatment $\times$ Egg mass & 10 & 0.055 & 0.005 & 2.054 & $0.047^{*}$ \\
\hline Error & 49 & 0.131 & 0.003 & & \\
\hline \multicolumn{6}{|l|}{ Aperture length } \\
\hline Treatment & 4 & 0.053 & 0.013 & 3.707 & $0.32^{\mathrm{ns}}$ \\
\hline Error & 12.772 & 0.046 & 0.004 & & \\
\hline Egg mass & 3 & 0.002 & 0.001 & 0.226 & $0.877^{\mathrm{ns}}$ \\
\hline Error & 13.619 & 0.049 & 0.004 & & \\
\hline Treatment $\times$ Egg mass & 10 & 0.035 & 0.003 & 0.702 & $0.718^{\mathrm{ns}}$ \\
\hline Error & 49 & 0.241 & 0.005 & & \\
\hline \multicolumn{6}{|l|}{ Aperture width } \\
\hline Treatment & 4 & 0.044 & 0.011 & 3.001 & $0.065^{\mathrm{ns}}$ \\
\hline Error & 11.361 & 0.042 & 0.004 & & \\
\hline Egg mass & 3 & 0 & 0.000489 & 0.013 & $0.998^{\mathrm{ns}}$ \\
\hline Error & 11.768 & 0.043 & 0.004 & & \\
\hline Treatment $\times$ Egg mass & 10 & 0.038 & 0.004 & 1.398 & $0.209^{\mathrm{ns}}$ \\
\hline Error & 49 & 0.132 & 0.003 & & \\
\hline \multicolumn{6}{|l|}{ Aspect ratio } \\
\hline Treatment & 4 & 0.112 & 0.028 & 5.703 & $0.006^{*}$ \\
\hline Error & 14.307 & 0.07 & 0.005 & & \\
\hline Egg mass & 3 & 0.04 & 0.013 & 2.666 & $0.084^{\mathrm{ns}}$ \\
\hline Error & 15.644 & 0.078 & 0.005 & & \\
\hline Treatment $\times$ Egg mass & 10 & 0.045 & 0.004 & 0.462 & $0.906^{\mathrm{ns}}$ \\
\hline Error & 49 & 0.473 & 0.01 & & \\
\hline \multicolumn{6}{|c|}{ Aperture length:Aperture width } \\
\hline Treatment & 4 & 5.563 & 1.391 & 5.029 & $0.014^{*}$ \\
\hline Error & 11.441 & 3.164 & 0.277 & & \\
\hline Egg mass & 3 & 0.562 & 0.187 & 0.681 & $0.581^{\mathrm{ns}}$ \\
\hline Error & 11.872 & 3.265 & 0.275 & & \\
\hline Treatment $\times$ Egg mass & 10 & 2.824 & 0.282 & 1.322 & $0.245^{\mathrm{ns}}$ \\
\hline Error & 49 & 10.463 & 0.214 & & \\
\hline \multicolumn{6}{|l|}{ Length:Aperture height } \\
\hline Treatment & 4 & 0.198 & 0.049 & 1.045 & $0.426^{\mathrm{ns}}$ \\
\hline Error & 11.427 & 0.541 & 0.047 & & \\
\hline Egg mass & 3 & 2.095 & 0.698 & 14.848 & $\leq 0.001^{* * *}$ \\
\hline Error & 11.854 & 0.558 & 0.047 & & \\
\hline Treatment $\times$ Egg mass & 10 & 0.483 & 0.048 & 1.335 & $0.239^{\mathrm{ns}}$ \\
\hline Error & 49 & 1.774 & 0.036 & & \\
\hline
\end{tabular}

(2003) studied the effects of tadpole exposure to different levels of predation risk at various stages during ontogeny on morphological and behavioural traits. $\mathrm{He}$ found that traits were highly reversible early in ontogeny in response to altered predation risk, but that reversibility was less later in ontogeny (Relyea 2003). The present study demonstrated plasticity, both morphological and physiological, in $R$. balthica embryos, but whether the window for this plasticity is restricted to embryonic development or continues through to adulthood is an area deserving of further work. At the same time, $R$. balthica is a mobile species and, therefore, in the presence of saline intrusion, could move inland. Although we can't excuse this ability as a potential mechanism by which this species might avoid salinity stress, the fact that it can inhabit waters approaching the upper salinity range (S7) as demonstrated in the present study (Råberg \& Kautsky 2007, Environment Agency pers. comm.), suggests that it may be able to maintain its current distribution and rely on its physiology for survival. As such, this species could offer important insights into which traits (including developmental plasticity and heterokairy) might allow the persistence of freshwater taxa under salinity stress.

Despite heterokairy having occurred in many of the developmental events studied, the appearance of the radula remained relatively fixed across treatments, occurring at the same time in development despite altered timing of the events occurring before and after (Fig. 2). Delayed hatching occurred in a salinity of 7 , but the radula (the event prior to hatching) did not occur significantly later in the S7 treatment compared with the APW treatment; there was therefore a prolonged period between radula and hatching during which little development was apparent. Arrested or reduced development rates under unfavourable conditions have been identified in many species (e.g. Wourms 1972, Petranka et al. 1982). Delayed hatching in embryos cultured under the S7 regime may be due to halted development in response to unfavourable conditions for the hatchling, as no visible development occurred in these embryos once radula ontogeny occurred. 


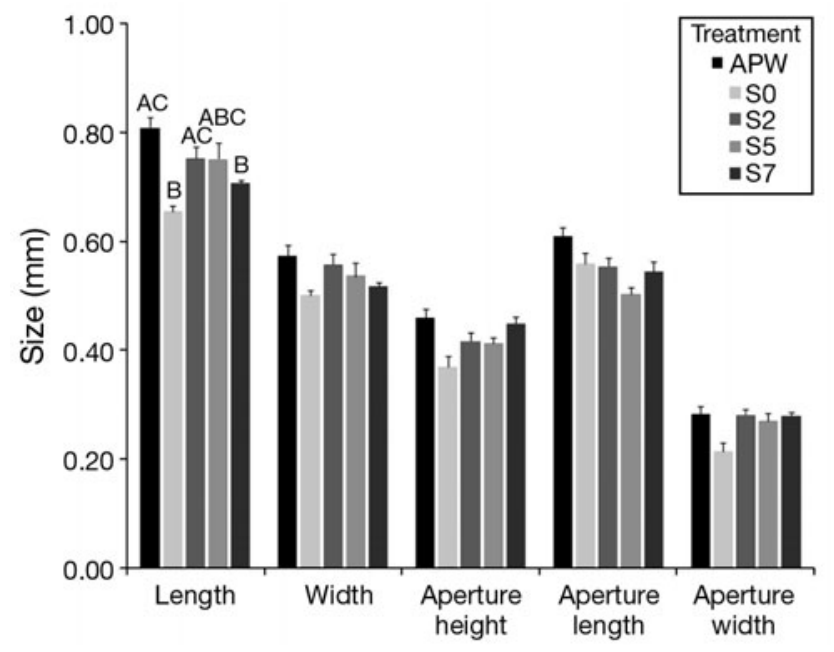

Fig. 5. Radix balthica. Mean $( \pm 1 \mathrm{SE})$ shell measurements between treatments. Results of post hoc pair-wise comparisons between treatments are indicated by different letters above error bars; similar letters indicate no significant difference as shown by post hoc Bonferroni tests. See Fig. 2 for description of treatments

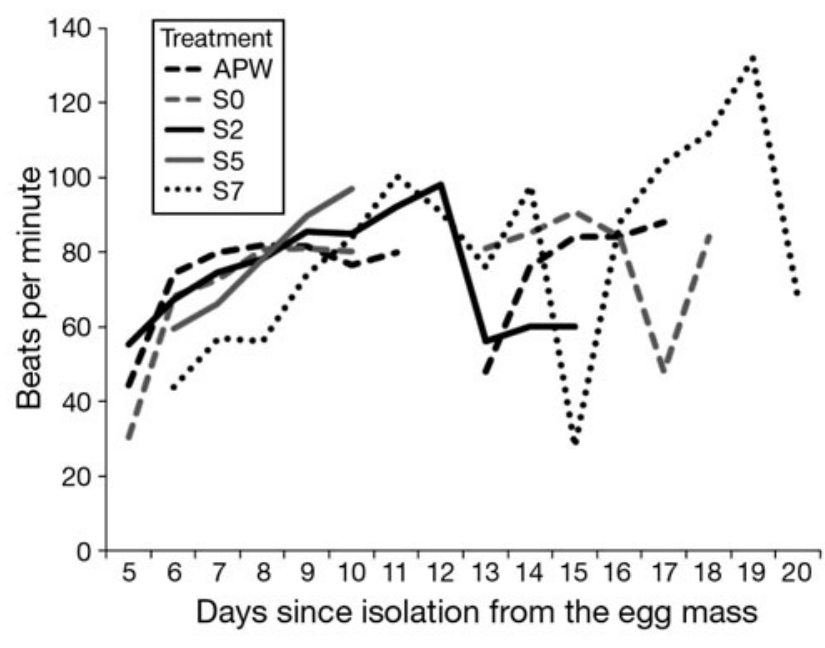

Fig. 6. Radix balthica. Mean heart rate measurements from first heartbeat through to hatching of individuals cultured within different treatment solutions. See Fig. 2 for description of treatments

The response of individual egg masses to salinity treatments in terms of survival and developmental event sequence and timing was highly variable. For example, survival of individuals through to hatching from a particular egg mass ranged from 0 to $100 \%$ in the S7 treatment. At the same time, the proportion of individuals within each egg mass exhibiting heterokairy (i.e. deviation in the sequence of developmental events from the mean developmental sequence recorded for the control APW treatment) in the S5 treatment ranged from 0 to $100 \%$, Smirthwaite et al.
(2007) recorded the same developmental sequence for this species in APW, which suggests our observed heterokairy is a deviation from the normal developmental sequence of this species; due to logistical constraints, only 4 egg masses were used in the present study and therefore caution is required in extrapolating to any population-level response. This high degree of variability in response to salinity between egg masses suggests there might be a large degree of genetic variation both within and between egg masses. Future studies that incorporate an investigation of the parentage of eggs within a mass, or that conduct selective breeding trials would be extremely valuable in elucidating key questions concerning the heritability of heterokairy. Such information would again be highly pertinent for predicting the potential that heterokairy might have in driving species responses to environmental change such as increased salinity in freshwater habitats.

In summary, in response to salinity, the upperestuarine Radix balthica embryos used in the present study exhibited plasticity both in the form of heterokairy (sequence and timing) in embryonic developmental events and in hatchling shell morphology. Heterokairy remains a form of plasticity of particular interest due to its possible evolutionary role as a mechanism by which differences in the developmental sequences between ancestral and descendent species (i.e. heterochrony) might evolve (Spicer \& Rundle 2007).

Acknowledgements. We thank J. Smirthwaite, M. Itsuji and R. Ticehurst for their technical assistance and advice.

\section{LITERATURE CITED}

Agrawal AA (2001) Phenotypic plasticity in the interaction and evolution of species. Science 294:321-326

Ahel M, Barlow RG, Mantoura RFC (1996) Effect of salinity gradients on the distribution of phytoplankton pigments in a stratified estuary. Mar Ecol Prog Ser 143:289-295

ASTM (American Society for Testing and Materials) (1980) Standard practice for conducting acute toxicity tests with fishes, macroinvertebrates and amphibians. ASTM, Philadelphia, PA

Bagatto B (2005) Ontogeny of cardiovascular control in zebrafish (Danio rerio): effects of developmental environment. Comp Biochem Physiol A 141:391-400

Black JL, Burggren WW (2004) Acclimation to hypothermic incubation in developing chicken embryos (Gallus domesticus) I. Developmental effects and chronic and acute metabolic adjustments. J Exp Biol 207:1543-1552

Blacker HA, Orgeig S, Daniels CB (2004) Hypoxic control of the development of the surfactant system in the chicken: evidence for physiological heterokairy. Am J Physiol Regul Integr Comp Physiol 287:R403-R410

Bradshaw AD (1965) Evolutionary significance of phenotypic plasticity in plants. Adv Genet 13:115-155

Carlsson R (2006) Freshwater snail assemblages of semi- 
isolated brackish water bays on the Åland Islands, SW Finland. Boreal Environ Res 11:371-382

de Lafontaine Y (1990) Distribution and abundance of ichthyoplankton in the Manicouagan river estuary, a tributary of the Lower St. Lawrence estuary. Estuaries 13:43-50

DeWitt TJ, Scheiner SM (eds) (2004) Phenotypic plasticity: functional and conceptual approaches. Oxford University Press, New York

> Gainey LF Jr, Greenberg MJ (1977) Physiological basis of the species abundance-salinity relationship in molluscs: a speculation. Mar Biol 40:41-49

Garland T Jr, Kelly SA (2006) Review: phenotypic plasticity and experimental evolution. J Exp Biol 209:2344-2361

Gotthard K, Nylin S (1995) Adaptive plasticity and plasticity as an adaptation: a selective review of plasticity in animal morphology and life history. Oikos 74:3-17

Harley CDG, Hughes AR, Hultgren KM, Miner BG and others (2006) The impacts of climate change in coastal marine systems. Ecol Lett 9:228-241

Hart BT, Bailey P, Edwards R, Hortle K and others (1991) A review of the salt sensitivity of the Australian freshwater biota. Hydrobiologia 210:105-144

IPCC (2001) Climate change 2001: Synthesis report. In: Watson TR and the Core Writing Team (eds) Contribution of Working Groups I, II, and III to the Third Assessment Report of the Intergovernmental Panel on Climate Change. Cambridge University Press, Cambridge

Jarne P, Delay B (1990) Inbreeding depression and selffertilization in Lymnaea peregra (Gastropoda: Pulmonata). Heredity 64:169-175

Jokela J, Wiehn J, Kopp K (2006) Among- and withinpopulation variation in outcrossing rate of a mixed-mating freshwater snail. Heredity 97:275-282

Knowlton N (2001) The future of coral reefs. Proc Natl Acad Sci USA 98:5419-5425

Lakowitz T, Brönmark C, Nyström P (2008) Tuning in to multiple predators: conflicting demands for shell morphology in a freshwater snail. Freshw Biol 53:2184-2191

Lam PKS, Calow P (1988) Differences in the shell shape of Lymnaea peregra (Müller) (Gastropoda: Pulmonata) from lotic and lentic habitats; environmental or genetic variance? J Molluscan Stud 54:197-207

Lee M (2001) Coastal defence and the Habitats Directive: predictions of habitat change in England and Wales. Geogr J $167: 39-56$

Morrill JB (1982) Developmental biology of the pulmonate gastropod, Lymnaea. In: Harrison FW, Cowden RR (eds) Developmental biology of freshwater invertebrates. Liss, New York, p 402-403

> Petranka JW, Just JJ, Crawford EC (1982) Hatching of amphibian embryos: the physiological trigger. Science 217:257-259

Pfenninger M, Cordellier M, Streit B (2006) Comparing the efficacy of morphologic and DNA-based taxonomy in the freshwater gastropod genus Radix (Basommatophora, Pulmonata). BMC Evol Biol 6:100

Pigliucci M (1998) Developmental phenotypic plasticity: where internal programming meets the external environment. Curr Opin Plant Biol 1:87-91

Pigliucci M (2001) Phenotypic plasticity; beyond nature and

Editorial responsibility: Hans Heinrich Janssen, Oldendorf/Luhe, Germany nurture. The Johns Hopkins University Press, Baltimore, MD

Pigliucci M (2005) Evolution of phenotypic plasticity: Where are we going now? Trends Ecol Evol 20:481-486

> Price TD, Qvarnstrom A, Irwin DE (2003) The role of phenotypic plasticity in driving genetic evolution. Proc R Soc Lond B 270:1433-1440

> Råberg S, Kautsky L (2007) A comparative biodiversity study of the associated fauna of perennial fucoids and filamentous algae. Estuar Coast Shelf Sci 73:249-258

> Relyea RA (2003) Predators come and predators go: the reversibility of predator-induced traits. Ecology 84:1840-1848

> Rundle SD, Spicer JI, Coleman RA, Vosper J, Soane J (2004) Environmental calcium modifies induced defenses in a freshwater gastropod. Proc Biol Sci 271(Suppl):67-70

Scavia D, Field JC, Boesch DF, Buddemeier RW, Burkett V, Cayan DR (2002) Climate change impacts on U.S. coastal and marine ecosystems. Estuaries 25:149-164

> Smirthwaite JJ, Rundle SD, Bininda-Emonds ORP, Spicer JI (2007) An integrative approach identifies developmental sequence heterochronies in freshwater basommatophoran snails. Evol Dev 9:122-130

Spicer JI, Burggren WW (2003) Development of physiological regulatory systems: altering the timing of crucial events. Zoology 106:91-99

Spicer JI, El-Gamal MM (1999) Hypoxia accelerates the development of respiratory regulation in brine shimp - but at a cost. J Exp Biol 202:3637-3646

Spicer JI, Rundle SD (2007) Plasticity in the timing of physiological development: Physiological heterokairy - What is it, how frequent is it, and does it matter? Comp Biochem Physiol A 148:712-719

Thain RH, Priestley AD, Davidson MA (2004) The formation of a tidal intrusion front at the mouth of a macrotidal, partially mixed estuary: a field study of the Dart estuary, UK. Estuar Coast Shelf Sci 61:161-172

- Warkentin KM (1995) Adaptive plasticity in hatching age: a response to predation risk trade-offs. Proc Natl Acad Sci USA 92:3507-3510

Warkentin KM (2007) Oxygen, gills, and embryo behavior: mechanisms of adaptive plasticity in hatching. Comp Biochem Physiol A 148:720-731

West-Eberhard MJ (1989) Phenotypic plasticity and the origins of diversity. Annu Rev Ecol Syst 20:249-278

West-Eberhard MJ (2003) Developmental plasticity and evolution. Oxford University Press, NY

West-Eberhard MJ (2005) Developmental plasticity and the origin of species differences. Proc Nat Acad Sci USA 102: 6543-6549

Wiehn J, Kopp K, Rezzonico S, Karttunen S, Jokela J (2002) Family-level covariation between parasite resistance and mating system in a hermaphroditic freshwater snail. Evolution 56:1454-1461

- Wourms JP (1972) The developmental biology of annual fishes. III. Pre-embryonic and embryonic diapause of variable duration in the eggs of annual fishes. J Exp Zool 182:389-414

> Yamamuro M (2000) Abundance and size distribution of sublittoral meiobenthos along estuarine salinity gradients. J Mar Syst 26:135-143

Submitted: December 5, 2008; Accepted: February 10, 2010 Proofs received from author(s): March 29, 2010 